\title{
Escritos sobre la violencia en la literatura argentina: "El matadero", de Esteban Echeverría y “Tablas de sangre”, de José Rivera Indarte
}

\section{Writtings about Violence in Argentine Literature: "El matadero", by Esteban Echeverría and "Tablas de sangre", by José Rivera Indarte}

\section{Resumen}

Este trabajo analiza el lugar central que ocupa "El matadero" dentro de una zona de la literatura argentina dedicada a la representación de la violencia y sus marcas sobre cuerpos y subjetividades, a través de una comparación con otro texto, también producido en el marco de la lucha simbólica que escritores argentinos mantuvieron contra el régimen de Rosas: "Tablas de sangre", de José Rivera Indarte. A partir de ese contrapunto, el presente trabajo quiere interrogarse sobre los factores que propiciaron la centralidad de "El matadero" dentro de una genealogía posible de escritos sobre la violencia en literatura nacional, corroborada en las incesantes relecturas críticas y reescrituras ficcionales que cosechó a lo largo de más de un siglo, mientras versiones más cruentas de los mismos acontecimientos y de la misma coyuntura histórica apenas fueron estudiadas y rondaron el olvido.

Palabras claves

Violencia, cuerpo, animalidad, literatura argentina

\begin{abstract}
This paper analyzes the central place that occupies "El matadero" within an area of Argentine literatura within an area of Argentine literature dedicated to the representation of violence and its marks on bodies and subjectivities, through a comparison with another text, also produced within the framework of the symbolic struggle that Argentine writers maintained
\end{abstract}


against the regime of Rosas: "Tablas de sangre by José Rivera Indarte. Based on this counterpoint, the present work wants to question about the factors that favored the centrality of "El matadero" within a possible genealogy of writings about violence in national literature, corroborated by the incessant re-readings and fictional rewritings that it harvested for more than a century, while more bloody versions of the same events and of the same historical conjuncture were hardly studied and they surrounded the oblivion.

Keywords

Violence, body, animality, Argentine literatura

En lo que al uso del cuchillo se refiere, las directivas de Juan Manuel de Rosas a sus subordinados son precisas y exigen precisión: “[la] degolladura de ningún modo se consentirá hacerla atravesada; debe ser a lo largo y medio a medio del pescuezo" (Rosas 84).

Si la forma de dar muerte se especifica y detalla, lo mismo ocurre con otras prácticas que anteceden o suceden a ese acto final: formas de la marcación a fuego, técnicas del desmembramiento, secretos para desollar un cuerpo sin arruinar el cuero, criterios de discriminación entre cabezas que deben acumularse en montones y las que deben clavarse en postes. Estas y otras instrucciones de Rosas a los mayordomos de sus estancias disponen una minuciosa serie de reglas, consejos y precauciones en el tratamiento del animal como capital, producto, vehículo y plaga, para domarlo, regular su desarrollo vital, explotarlo e incluso exterminarlo. Según se lee en los clásicos de la literatura del antirrosismo, sobre estos mismos procedimientos se habría fundado la maquinaria represiva del régimen; de ahí, uno de sus tópicos principales, retomado incluso por ciertas zonas del discurso historiográfico: ${ }^{1}$ Rosas gobierna Buenos Aires como una estancia y a sus habitantes, como a animales. En la equiparación entre animales y hombres, o entre ciertos animales y ciertos hombres, radicaría la lógica de funcionamiento y, a la vez, la condición de posibilidad de los ultrajes cometidos en nombre del tirano. Marcas, torturas, cautiverios y modalidades de ejecución como el degüello constituyen

${ }^{1}$ Quizá el más representativo ejemplo sea el Juan Manuel de Rosas, de John Lynch, con sus capítulos "Patrón y peón", "Leviatán" y "Terror", en los que se reproduce, de manera acrítica y casi sin variantes, la perspectiva de los detractores contemporáneos de Rosas y su régimen. 
prácticas que despojan a los sujetos que las padecen de su estatuto humano al conferirles un trato propio del que se dispensa a la vida animal. En lo simbólico y en lo material, en el discurso y en la praxis, el poder soberano de Rosas desnudaría la vida humana de toda protección, hasta volverla tan prescindible y sacrificable como la del ganado o la de los animales de rapiña a los ojos del patrón de estancia. ${ }^{2}$ En última instancia, como señala Mónica Cragnolini, en eso consiste la "lógica del sacrificio" (35): en naturalizar la muerte animal en manos del hombre y en empujar a ciertos humanos hacia "modos de lo animal para asumir 'sin culpas' la 'necesidad' de su desaparición" (35).

El canon que la crítica literaria consolidó hacia mediados del siglo XX incluye dos versiones principales de este modo de entender y figurar las violencias del rosismo sobre el cuerpo de sus enemigos políticos. Una de ellas se integra al núcleo argumental del ensayo mayor sobre el período:

Rosas se distingue desde temprano en la campaña por las vastas empresas de leguas de siembras de trigo que acomete y lleva a cabo con suceso, y sobre todo por la administración severa, por la disciplina de hierro que introduce en sus estancias. Esta es su obra maestra, su tipo de Gobierno, que ensayará más tarde para la ciudad misma [...].

¿Dónde, pues, ha estudiado este hombre el plan de innovaciones que introduce en su gobierno en desprecio del sentido común, de la conciencia y de la práctica inmemorial de los pueblos civilizados? Dios me perdone si me equivoco, pero esta idea me domina hace tiempo: en la Estancia de ganados en que ha pasado toda su vida, y en la Inquisición, en cuya tradición ha sido educado. (Sarmiento 237-238, subrayado del autor)

\footnotetext{
${ }^{2} \mathrm{La}$ animalización que la literatura y la prensa del antirrosismo denuncia como mecanismo de sometimiento por parte del régimen se complementa con otra, que va en sentido contrario: Rosas y sus partidarios son bestias, animales, seres monstruosos que mixturan lo humano y lo animal. La figura dilecta, tanto en los discursos como en las imágenes que se esgrimen como estrategia de difamación, es la del tigre.
} 
Que Sarmiento identifique en la estancia un laboratorio donde Rosas habría puesto a prueba su sistema de poder, para proyectarlo luego a gran escala, promueve dos series de razonamientos diferentes, ambas claves en el Facundo. Por un lado, la idea de que Rosas no representa, como Facundo Quiroga, la potencia desatada de la barbarie, sino su versión sistemática, calculada. Por el otro, la idea de que su régimen de poder rebaja "la condición humana equiparándola a la del animal" (Lojo 63). ${ }^{3}$ En los términos de la analogía, la provincia equivale a la estancia, los subordinados a los peones y los enemigos políticos, desde luego, al ganado.

Sarmiento quiere decodificar la lógica de funcionamiento de la tiranía de Rosas; entender los engranajes de esa máquina de poder resulta crucial para su proyecto literario y político. Enuncia y denuncia el plan sistemático que Rosas pone en marcha, su perversión del rol del gobernador al mimetizarlo con la figura del estanciero, su perversión de la condición humana al reducirla a la animalidad. En cambio, en "El matadero", de Esteban Echeverría, la otra versión canónica sobre la violencia animalizante en tiempos de Rosas, el leve desplazamiento en la geografía de la cadena productiva, de la estancia al matadero, se corrobora en otros más significativos a nivel textual: el ensayo cede su lugar al relato y la descripción, que se imponen por sobre la mirada analítica. No se tratará ya de develar, como en el Facundo, las estrategias a través de las cuales Rosas somete a los hombres, los domestica, los vuelve animales sacrificables, sino de exhibirlas en primer plano: "El matadero" figura una escena, un territorio, un lenguaje, un cierto tipo de relaciones económicas, políticas y sociales, en los cuales distintas modulaciones de la violencia desdibujan el límite entre lo humano y lo animal hasta tornarlo indistinguible. La más álgida instancia de la narración, en ese sentido, será la conocida escena en la que un joven unitario resulte sometido por los bárbaros federales del matadero de la Convalecencia. En ella, una turba de rosistas

${ }^{3}$ Presentada a la manera de una reducción, la equiparación entre vidas humanas y animales que denuncian los escritores del antirrosismo reproduce, a su modo, una larga tradición del pensamiento occidental que concibe la vida animal por oposición a la vida humana y en los en los términos de la carencia. Carencia de palabra, de razón, de logos, de historia, de risa, de duelo, entre otras muchas cosas que, según Derrida, engrosan la lista sin clausura de atributos con que la filosofía pretende definir "lo propio del hombre" (Derrida 19). 
CATEDRAL TOMADA: Revista de crítica literaria latinoamericana / Journal of Latin American Literary Criticism Escritos sobre la violencia en la literatura argentina: “El matadero", de Esteban Echeverría y "Tablas de sangre”, de José Rivera Indarte

enfervorizados captura una vida humana y comienza su proceso de equiparación con la del resto de los animales sacrificados en ese mismo escenario, en ese mismo relato.

Entonces: si la manifestación más cabal de la violencia política ejercida por el régimen de Rosas es presentada bajo la forma de ese proceso de animalización del enemigo, y si "El matadero" es interpretado como su más cruenta cristalización literaria, que se lo catalogue como el texto por antonomasia sobre las violencias de aquel período parece tan lógico como previsible. Sin embargo, inédito hasta 1871, el texto de Echeverría condensa temas, tonos y figuraciones que circulaban profusamente en diversas textualidades contemporáneas al hipotético momento de su escritura. ${ }^{4}$ La prensa facciosa que los exiliados argentinos publicaron en Montevideo, por caso, redunda en atribuir a Rosas y sus seguidores un inconmensurable derrotero de crímenes, caracterizados por una brutalidad y crueldad que tiñen a Buenos Aires del color de la sangre. Así, El grito arjentino responsabiliza a Rosas de orquestar "una carnicería" (6 junio, 1839) contra los opositores a su régimen, mientras que el Muera Rosas! acusa a las huestes del rosismo de haber "degollado hombres con el mismo empeño, con la misma ferocidad é indiferencia, que se degüellan novillos en un matadero" (23 diciembre, $1841)$.

Aun cuando la proximidad de estas analogías con la escena que configura el texto de Echeverría sugiera que unas y otra responden a elementos disponibles en el imaginario de la época, "El matadero" recibió lecturas y relecturas permanentes, desde su primera publicación hasta hoy, mientras que otras manifestaciones de un antirrosismo igual de pertinaz apenas comienzan a ser abordadas en estudios recientes. ${ }^{5}$ Primer cuento nacional, ficción en tiempos en que la ficción escaseaba,

${ }^{4}$ Es sabido que las especulaciones críticas sugieren como fecha plausible de escritura de "El matadero" los años que van desde 1838 a 1840 . Probablemente, el único reparo a ese consenso generalizado sea el de Emilio Carilla, quien destaca, no sin argumentos a su favor, que la crítica parece homologar sin mediaciones la data de la escritura con "la cronología temática señalada por el autor al comienzo del relato" (120-121).

${ }^{5}$ Por mencionar algunos textos que se orientan en ese sentido, Barbarie y civilización: sangre, monstruos y vampiros durante el segundo gobierno de Rosas, de Gabo Ferro (2008) y "Caricatura 
texto enigmático por su publicación diferida, primera representación de las prácticas y la lengua de los otros por fuera de la poesía gauchesca, si todos esos factores le confirieron, en sí mismos, centralidad dentro del canon de las letras argentinas, "El matadero" también habría de ser leído como ejemplo primordial y extremo de los modos en que la literatura asumió el tratamiento de las distintas formas de violencia ejercidas durante el gobierno de Rosas.

El más célebre de sus paratextos, la "Advertencia” con que Juan María Gutiérrez acompañó su primera publicación en la Revista del Río de la Plata, ya comienza a trazar un itinerario en ese sentido. A la vez que se esmera en asimilarlo al proyecto estético e ideológico de su autor, sugiriendo que se trata de un boceto o un conjunto de notas apresuradas, refundidas luego en obras mayores como el Avellaneda, Gutiérrez también confiere a "El matadero" otros dos rasgos distintivos, en relativa tensión con ese esfuerzo inicial. El primero de ellos, un carácter documental único: si la historia, las costumbres y los tipos sociales del pasado argentino se difuminan por no haber tenido hasta entonces "arte ni literatura nacional" (Gutiérrez 97) que los registren, el texto de Echeverría reluce, en la perspectiva de Gutiérrez, como una venturosa anomalía. El segundo rasgo, la cruda versión de la realidad histórica que retrata, propiciada por el afán de Echeverría de ser fiel a su percepción de la época que le tocó vivir: "los colores de este cuadro son altos y rojizos, pero no exagerados" (99).

"El matadero", entonces, como testimonio cruento y esforzadamente fiel, pero también incomparable, único en el más estricto sentido de la palabra. Echeverría lega (de manera accidental, habría que suponer, si se es coherente con la interpretación del texto como mero ejercicio) un documento que representa sin eufemismos ni exageración la barbarie desatada que imperó en épocas de Rosas, y

y Política en El Grito Argentino (1839) y ¡Muera Rosas! (1841-1842)”, de Claudia Román (2005), abordan la producción de la prensa periódica antirrosista. Por su parte, durante las últimas tres décadas, los textos de José Rivera Indarte merecieron la atención de tres estudios críticos que analizan en ellos la representación extrema de la violencia política en tiempos de Rosas. Se trata de La máquina infernal. Apuntes sobre Rivera Indarte, de Nicolás Lucero (1992), "Proferir lo inaudito: 'Tablas de sangre', de José Rivera Indarte”, de Leila Area (2006), y “Avatares de una cabeza en la picota: los restos insepultos como significante en disputa en algunos textos de José Rivera Indarte", de Sofía Traballi (2015). 
CATEDRAL TOMADA: Revista de crítica literaria latinoamericana / Journal of Latin American Literary Criticism Escritos sobre la violencia en la literatura argentina: “El matadero", de Esteban Echeverría y "Tablas de sangre”, de José Rivera Indarte

Gutiérrez, en su rol de albacea, lo da a conocer justo a tiempo para subsanar el peligro de olvido que se cierne sobre dicho período histórico: ${ }^{6}$

Hemos pasado por una verdadera época de terrorismo que infundió admiración y escándalo en América y Europa. Pero si se nos pidieran testimonios y justificativos escritos para dar autenticidad a los hechos que caracterizan aquella época, no podríamos presentarlos, ni siquiera narraciones metódicas y anecdóticas, a pesar de oírlas referir diariamente de boca de los testigos presenciales. Cuando estos dejen de existir estamos expuestos a que se crea que no hemos sido víctimas de un bárbaro exquisitamente cruel, sino de una pesadilla durante el sopor de una siesta de verano. (100)

Las operaciones de lectura que Gutiérrez despliega en la "Advertencia" tienden a dotar a "El matadero" de un valor documental que subsane o disculpe lo que, a sus ojos, sin duda, constituyen exabruptos o desatinos en el plano de lo estético. En el discurrir de su argumentación, la valoración del texto echeverriano irá oscilando entre una aparente relativización de su densidad literaria y una sobrestimación marcada de su costado testimonial. En uno y otro sentido, la categoría con que Gutiérrrez parece decidido a catalogar a "El matadero" es la de la excepcionalidad: excepcional dentro de la obra de su autor, excepcional en su programa estético e ideológico, excepcional entre los demás textos producidos como reacción a la tiranía de Rosas, excepcional por la intensidad de sus tonos, por la violencia que traduce, por la exactitud y valentía con que se retrata una época atroz que, de otro modo, habría sido olvidada para siempre.

Aun cuando la crítica literaria se haya ocupado de desmontar con minucia el entramado de argumentos, conjeturas y juicios de valor que la "Advertencia"

\footnotetext{
${ }^{6}$ Desde la perspectiva de Carilla, no obstante, habría que sumar otra faceta del trabajo de Gutiérrez sobre "El matadero", la más decisiva y, a la vez, la más difícil de corroborar: la faceta del colaborador, que revisa y retoca el texto, que lo corrige y, quizás, incluso lo completa.
} 
sobreimprime, como un protocolo de lectura, al texto que acompaña, existe por lo menos un aspecto en el cual la mirada de Gutiérrez parece haberse impuesto. ${ }^{7}$ Porque, cuando lecturas tan clásicas como las de David Viñas o Ricardo Piglia se aproximen a "El matadero" para postularlo en los orígenes mismos de una literatura nacional gestada bajo el signo de la violencia y la política (la violencia política), no considerarán necesario poner en contexto sus tópicos, sus tonos, su retórica, como así tampoco indagar en el imaginario del que se nutre. Les bastará, en cambio, con sugerir únicamente un diálogo mínimo con otros textos del canon romántico, como Amalia o el propio Facundo. En ese corpus selectivo, el texto de Echeverría conserva parte de su excepcionalidad: su carácter de nota saliente, virulenta y encendida. ${ }^{8}$

Junto con los abordajes críticos que se sucedieron, casi sin interrupción, en esa misma línea, los modos en que nuevas ficciones remiten a "El matadero", abrevan en su imaginario, lo citan, lo aluden, lo distorsionan, lo actualizan, terminan de ratificar su condición de texto inaugural de una tradición. Como propone Gabriel Giorgi, sería posible pensar "una constelación de reescrituras y versiones del texto de Echeverría, que pasan por Borges y Bioy Casares, Lamborghini, Viñas, Carlos Alonso [...] entre otros" (Giorgi 132), una gama de textos que, de manera tácita o explícita, dialogan con "El matadero" y lo sitúan en el punto de partida de una modalidad de aproximación, a través de la ficción, a los avatares de la lucha política en Argentina y a sus marcas sobre las vidas, las subjetividades y los cuerpos. Lejos de quedar circunscripto a la faceta documental que reivindicó Gutiérrez, el texto de Echeverría se ofrece, así, como un dispositivo literario eficaz aún por fuera de la referencia precisa a la época a la que alude.

${ }^{7}$ De algún modo, en este aspecto continuaría todavía vigente parte de esa "credulidad de la crítica" (Carilla 114) frente a la lectura de Gutiérrez, que Carilla atribuye al prestigio que circunda su figura.

${ }^{8}$ Viñas vincula "El matadero" con Amalia en torno a la idea, tan mentada como efectista, de que "la literatura argentina emerge alrededor de una metáfora mayor: la violación" (Viñas 15). Piglia, por su parte, emplaza el doble comienzo de la literatura nacional en la duplicación de un mismo relato: el vejamen del unitario, al final del cuento de Echeverría, y el ennoblecido escape de Sarmiento en las páginas iniciales del Facundo (Piglia 8). 
Ahora bien, ¿sobre qué rasgos de "El matadero" descansa esa eficacia? ¿En qué elementos se cifra esa invitación sostenida a la reescritura? ¿Son los mismos que renuevan la voluntad crítica de leerlo y pensarlo, una y otra vez? O, en otros términos: ¿qué hizo que "El matadero", primer cuento nacional, ficción en tiempos en que la ficción escaseaba, texto enigmático por su publicación diferida, primera representación de las prácticas y la lengua de los otros por fuera de la poesía gauchesca, sea también posicionado como texto clave, primigenio y modélico sobre las violencias animalizantes del rosismo, en particular, y sobre las violencias deshumanizantes de la política en la historia argentina, en general? Porque, no sólo los temas, tonos y figuras que despliega no le son exclusivos, como se comprueba, por caso, en una lectura sumaria de los diarios antirrosistas ya citados, sino que, además, esos colores "altos y rojizos" que destaca Gutiérrez, sobresalientes dentro del corpus de textos de la época que el canon privilegia, comienzan a atenuarse cuando el terreno de la comparación se extiende. El propio Echeverría, por ejemplo, hace constar su aversión frente al grado de virulencia que alcanza el discurso de uno de sus contemporáneos:

¿[q]ué doctrina social ha formulado usted en su apostolado de cinco años en El Nacional; qué idea nueva ha emitido, qué importación inteligente nos ha inoculado, qué poesía original nos ha revelado, qué intuición de su genio nos ha embutido? [...] ¡Apostolado para el pueblo, dice usted! Apostolado de sangre, de difamación, de inmundicia. (Echeverría "Tercera carta" 181)

El destinatario de esos reproches es José Rivera Indarte, el mismo que, antes de exiliarse en Montevideo, convertirse en editor de El Nacional desde 1839 y desplegar una generosa producción escrita al servicio de su prédica contra el rosismo, había saludado con un "Himno de los Restauradores" el regreso de Rosas a la gobernación, en 1835. El irrevocable mote de converso que le valió su trayectoria sinuosa terminaría por transformarlo en blanco dilecto de críticas parejas 
por parte de ambos bandos: si Echeverría lo fustiga en más de una ocasión, Nicolás Mariño y Pedro de Angelis, antiguos compañeros de facción, no son más condescendientes. Junto con la sospecha por su pasado espurio, de un lado, y el reproche de traición, por el otro, resulta significativo, no obstante, que las críticas dirigidas a Rivera Indarte, desde todos los flancos, terminen por coincidir en un mismo juicio de base: la intolerable y desmesurada violencia de su literatura de propaganda. Así, a una y otra orilla del Río de la Plata, se lo censuraría por radicalizar hasta el límite el ejercicio de la escritura facciosa, primero con provocaciones y descalificaciones a los enemigos de Rosas, luego en estricto sentido contrario.

Tempranamente, la figura de Rivera Indarte comienza a cristalizarse en pocos y simplificadores rasgos que su muerte, la adscripción política de quien los esgrima y las relecturas de varias décadas posteriores dejarán casi inmutables: un escritor virulento, una escritura infame y difamatoria, un hombre de dudosa moral, convicciones mudables, trayectoria zigzagueante. Entre el descrédito a su persona y a su oficio, sancionado desde una perspectiva que entremezcla juicios moralistas, ideológicos y de purismo estético — sin olvidar miserables rencillas personales-, ya no será releído por fuera de los parámetros que demarcan esas primeras aproximaciones. En esos términos, y “con muchas reservas” (Rojas 484), ingresará Rivera Indarte a la primera Historia de la literatura argentina. Para Rojas, en efecto, su prosa, de cuestionable o nula calidad literaria, constituye únicamente un “documento de esa airada elocuencia del rencor que asumió a veces la propaganda de los emigrados." (484). No muy lejos de esa sentencia, Adolfo Saldías, en cuya Historia de la Confederación Argentina Rivera Indarte se posiciona como el más extremo publicista del antirrosismo, sostendrá que "su pluma solo corrió a impulsos de las pasiones vergonzantes de la época" (Saldías 333). Incluso Bartolomé Mitre, amigo, biógrafo y editor post mortem de su antología de poemas, articulará uno de sus principales elogios sobre los mismos presupuestos: 
Su rol fue esencialmente militante, y sus escritos llevaban el sello de los boletines sahumados por la pólvora del combate. Una pluma era su espada; una hoja de papel su baluarte; las palabras eran sus proyectiles: y como para dar más realce a este rol militante solo le faltaba morir como el soldado al pie de su bandera, murió exhausto de fatiga, oprimiendo la acerada pluma del escritor político. (Mitre 35)

La uniformidad en los juicios sobre Rivera Indarte terminará por propiciar una paradoja: proclamado escritor de la virulencia, la difamación y la desmesura, esas mismas etiquetas, al simplificar la lectura de sus textos, clausurarán su análisis en una serie literaria que aborde, precisamente, el triple vínculo entre literatura, violencia y política. Convertido en una página menor de la tradición argentina, una firma eclipsada a perpetuidad por los nombres mayores del romanticismo rioplatense, Rivera Indarte se mantendrá en la zaga incluso cuando la crítica y la ficción relean las inflexiones más álgidas de la violencia en la literatura nacional.

Y, sin embargo, en esos textos que Echeverría desprecia por su inflamación retórica, por su regodeo en la sangre y la inmundicia, parecen cifrase, en versiones más extremas, algunos de los rasgos que caracterizan a "El matadero". Leído a la luz de, por caso, "Tablas de sangre", no resulta ocioso preguntarse por qué, independientemente del lugar que otros factores le hayan deparado a uno y otro texto en el canon literario nacional, el primero es eje de una genealogía posible sobre las versiones literarias de la lucha política en Argentina y sus trágicas huellas sobre sujetos y cuerpos, mientras que al otro le fue deparado el lugar de la nota al pie, el comentario o el olvido, si un cotejo entre ambos, de hecho, permite advertir que, con el foco de atención circunscripto a la deshumanización del otro, a la animalización del enemigo político, a la desarticulación de la diferencia entre vida y muerte de humanos y animales como mecanismo de figuración literaria de la violencia política, es "Tablas de sangre" el que se exhibe como más crudo y radicalizado. 
Una respuesta tentativa parece asomar en ese mismo cotejo: en función de las muchas diferencias que, sobrepuestas a las coincidencias iniciales, distancian a "El matadero" de "Tablas de sangre" (diferencias de estatuto, de circulación, de apuesta estética y política), vuelven a relucir como claves en la entronización del primero dentro de una genealogía literaria de la violencia aquellos factores que lo distinguen como texto canónico de por sí. No se trata, no obstante, de proponer por toda hipótesis una mera centralidad contagiada, o una incapacidad de las lecturas y reescrituras constantes de "El matadero" para alumbrar zonas menos transitadas de la literatura nacional. Por el contrario, se trata de proponer un análisis que tienda a dilucidar de qué manera los mismos rasgos que le labraron un privilegiado lugar en el canon nacional, en particular ese carácter singular de ficción inaugural y desplazada, de texto clave de y sobre un período en el que no fue leído, tienden a redoblar la significación y la eficacia de su representación literaria de la violencia, aun cuando, situada en el contexto de otros escritos antirrosistas menos frecuentados, esa excepcionalidad de tema y tono que, desde Gutiérrez en adelante, se le suele atribuir comience a atenuarse.

\section{Echeverría, Rivera Indarte y el apostolado contra Rosas}

En 1844, una velada literaria, organizada por Andrés Lamas y celebrada en el teatro del Comercio de Montevideo con motivo de las Fiestas Mayas, reunió a siete poetas rioplatenses para la lectura en público de composiciones alusivas. ${ }^{9}$ Dos días más tarde, una crónica del evento, publicada en El Nacional, daría pie a una polémica que convertiría en declarada la hasta entonces sorda rivalidad entre dos de los participantes.

Rivera Indarte, en su doble condición de editor del diario y animador de la velada, ofrece una versión de los hechos de la que se desprende, sin ambigüedad,

\footnotetext{
${ }^{9}$ Participaron de la velada Francisco Acuña de Figueroa, Bartolomé Mitre, José María Cantilo, Luis Domínguez y Alejandro Magariños, además de Echeverría y Rivera Indarte.
} 
que la composición leída por Luis Domínguez resultó la más celebrada por el público. Echeverría y su más que sensible orgullo no demorarán en responder, primero con tibieza y cordialidad, luego con franco enojo, a esas apreciaciones.

Para Echeverría, la reconstrucción que hace Rivera Indarte no sólo es errónea, sino calculada con la voluntad de disimular que su participación fue tan exitosa y aplaudida como la de Domínguez. Todavía no entregado a la confrontación lisa y llana, Rivera Indarte responde, en primera instancia, con ironía: aclara, en primer lugar, que, si no destacó de manera singular la reacción del público ante la composición de Echeverría, fue por no recordar que el público mismo lo hubiera hecho; saluda, en segundo lugar, que las Fiestas Mayas hayan ofrecido al poeta laureado la ocasión de comenzar "dignamente su apostolado contra Rosas" (Rivera Indarte "Respuesta” 166).

En ese punto, la polémica tuerce su rumbo para vertebrarse sobre otro eje. En las cartas públicas y privadas que ambos contendientes harán circular en lo sucesivo, la cuantificación imposible de los aplausos recibidos el 25 de mayo irá mereciendo cada vez menos atención, desplazada por otra disputa: quién acumula más méritos como escritor del antirrosismo.

Echeverría se defiende a través de un convite: sugerirá a su interlocutor que “pase por mi casa, a ver si gusta, los documentos" (Echeverría 166) que permitirían corroborar la antiguiedad de su postura política, preexistente, según remarca, al exilio en Montevideo. Rivera Indarte, en cambio, redobla su ataque con un desafío: mejor que una lectura individual y privada de ese material, sería que Echeverría "lo imprima para que el público lo conozca” (Rivera Indarte “Tercera carta” 168).

Ambas invitaciones resultarían desoídas. Se sabe, por los últimos coletazos de la polémica, que Rivera Indarte no visitó la casa de Echeverría para zanjar diferencias ni leyó los textos aludidos. Y se sabe, por la labor de albacea que Gutiérrez llevaría a cabo casi tres décadas después, que Echeverría tampoco dio a conocer íntegramente los papeles que documentaban su temprana prédica antirrosista; "El matadero", el texto que mejor hubiera podido refrendar esa 
posición, presumiblemente escrito cuatro o cinco años antes de la discusión, permanecería inédito hasta 1871.

Pero "El matadero" no sólo constituye el documento temprano y contundente con que Echeverría hubiera podido rebatir la ironía de Rivera Indarte: también representa el mayor grado de aproximación entre la literatura que los polemistas de 1844 produjeron como reacción al rosismo. Como en ninguna otra zona de la escritura de Echeverría, Rivera Indarte hubiera podido leer en "El matadero" una tópica y una retórica que procesan, en otra clave, las mismas denuncias contra el régimen efectuadas por él en "Tablas de sangre”. Justamente el texto que Echeverría elige no publicar es el que aproxima su escritura a esa zona de la literatura de su época que rezuma "sangre" e "inmundicia" y que lo mueve al desprecio.

A priori, una lectura en conjunto de "El matadero" y "Tablas de sangre" parece acentuar, sobre todo, el contraste. Contraste, por empezar, en sus modos de circulación: mientras que el texto de Echeverría fue publicado en la Revista del Río de la Plata, en 1871, a dos décadas de la muerte de su autor, y luego incorporado de inmediato en el ambicioso proyecto editorial de las Obras Completas que dirigió Gutiérrez, el texto de Rivera Indarte, en cambio, se entreveró con la coyuntura política y propagandística a la que alude, conoció una primera versión, publicada en El Nacional bajo el título de "Efemérides de los degüellos y matanzas de Rosas", fue refundido en un folleto de 1842, ya con el título de "Tablas de sangre", e incorporado, finalmente, como apéndice del libro de 1843, Rosas y sus opositores. Contraste, además, y como consecuencia de lo anterior, en los modos de recepción: si el sostenido carácter de inédito que ostentó por décadas puso a "El matadero" por fuera del fuego cruzado que exacerbó la lucha simbólica en tiempos de Rosas, las denuncias emitidas por Rivera Indarte, los nombres propios involucrados, las fechas, los hechos, las cifras de asesinatos y ejecuciones que multiplica, merecieron una enérgica contraofensiva, bajo la forma de la desmentida o la injuria, por parte de La Gaceta Mercantil y otros órganos de propaganda oficial. Contraste, finalmente, entre dos textos que persiguen para sí una dimensión política e histórica, 
pero que apelan a estrategias diferentes y reclaman distintos criterios de verdad. De un lado, "El matadero" y su decurso de lo real hacia la ficción, del cuadro de costumbres al cuento, según el clásico análisis de Noé Jitrik (1971); del otro, "Tablas de sangre", con su retórica de hipotética neutralidad y sus entradas alfabéticamente ordenadas que, "a la manera de un implacable y gélido diccionario" (Area 199), —calculado enmascaramiento de la función propagandística detrás de una supuesta precisión estadística e histórica- pretende registrar todas las violencias del rosismo desde 1829 hasta 1843.

Y, sin embargo, ambos textos mantienen un eje compartido sobre el cual se articulan las visiones de sus respectivos autores sobre el enemigo que parcialmente aúna voluntades, proyectos literarios y egos irreconciliables. Ese lugar común, que emparenta el texto secreto del primer poeta del romanticismo rioplatense con la escritura virulenta del contemporáneo al que desprecia, se cifra en la escena que "El matadero" ficcionaliza una vez y que "Tablas de sangre" multiplica hasta lo inconmensurable: la escena en que los partidarios de Rosas toman en sus manos una vida humana, la someten, la desnudan, la degradan, la conducen hacia la animalidad. Porque si algo hilvana las múltiples denuncias que se suceden en las entradas alfabéticas del texto de Rivera Indarte y las emparenta con los episodios que se precipitan hacia el final del cuento de Echeverría es esa convicción de que el poder soberano de Rosas opera como una fuerza animalizante que se adueña del cuerpo de sus enemigos políticos y los somete a prácticas propias de la actividad pecuaria.

En el fragor del debate de 1844, Echeverría arremeterá contra la literatura facciosa de Rivera Indarte, tildándola de inmunda y sangrienta. Su lapidaria opinión parece sugerir un límite ético y estético dentro del cual circunscribir esa práctica que también constituye un terreno de competencia para los recelosos polemistas y que recibe el significativo mote de apostolado contra Rosas. Un límite doble, en todo caso, que Echeverría traza en la forma más que en el contenido mismo de los textos: el género y el tono del Avellaneda, por ejemplo, lo convierten en un texto valioso, aceptable, publicable, aun cuando multiplique escenas en las cuales el 
brazo armado del rosismo ejercita sus violencias sobre los cuerpos enemigos desbaratando su forma humana y mixturándola con la animal. El Avellaneda es, para Echeverría y su época, todo lo que "El matadero" (y, podría agregarse, "Tablas de sangre") no: texto definible en cuanto a su taxonomía genérica, texto definido en cuanto a su posicionamiento estético, texto que define, por igual en su aspecto ideológico y estético, el lugar de los héroes y mártires, de un lado, y de los villanos bestiales y monstruosos, del otro; texto capaz, en otras palabras, de integrarse al proyecto echeverriano sin ponerlo en crisis ni disonar con la paleta atenuada (por recuperar la analogía cromática de Gutiérrez) que predomina en él.

Considerando, entonces, ese límite implícito que Echeverría sugiere, tanto "El matadero" como "Tablas de sangre" caerían del lado de la transgresión: ambos llevan a un extremo intolerable el uso político de la literatura. Pero la naturaleza de esa transgresión es, en ambos casos, a la vez idéntica y diferente. Su punto de partida resulta común: la puesta en escritura de las múltiples violencias atribuidas a Rosas y sus partidarios, que tienden al sometimiento, la tortura, la aniquilación y la animalización de la subjetividad y corporalidad de sus enemigos. Las estrategias que dominan cada representación, en cambio, son las que trazan la distinción.

\section{"Tablas de sangre": diccionario de la barbarie}

Echeverría, es sabido, apuesta a construir su escena desde el detalle, a situarla en una atmósfera densa que debe ser arduamente descripta, incluso ordenada previamente con la exactitud de un croquis, porque es "para vista no para escrita" (Echeverría "El matadero" 110). Con la misma voluntad de precisión, que Gutiérrez lee en clave testimonial y que habilitó la reivindicación de Echeverría como precursor del realismo y el naturalismo en el Río de la Plata, ${ }^{10}$ serán perfilados

\footnotetext{
${ }^{10}$ Luis Tamini, en una serie de ensayos publicados en La Nación hacia fines de 1880, y Martín García Merou, en su Ensayo sobre Echeverría, sugieren que "El matadero" anticipa la llegada al Río de la Plata de la escuela de Emile Zola.
} 
los personajes que componen "la chusma" (109) del matadero. ${ }^{11}$ Ese efecto, sin embargo, no se desprenderá tanto de su caracterización física o de su individuación como personajes, sino del verismo que Echeverría imprime a la jerga que les atribuye. "[A]contecimiento histórico" (Piglia 9) para la literatura argentina, la representación de esa lengua popular que comparten achuradores, carniceros, negras y mazorqueros, no sólo se recorta contra la artificiosa oralidad del unitario y se desborda hasta impregnar ciertas zonas del discurso del narrador: constituye también el punto máximo de la transgresión de Echeverría sobre su propia poética, el quiebre irreconciliable con la engolada representación de la violencia que asume en el Avellaneda. Más aún, en el lenguaje de la "chusma" se condensa la matriz de violencia que atraviesa el texto, no sólo porque la jerga vulgar violente las normas lingüísticas y pervierta la lengua noble que el unitario sabe hablar en su registro más elevado, o porque la oralidad de los federales no conozca pruritos ni eufemismos y apueste a "producir con palabras el efecto de violentar al lector" (Iglesia 24), sino también porque en "El matadero" buena parte de las acciones que implican el ejercicio de la violencia física se quedan en la amenaza, son enunciadas más que ejecutadas.

"Tablas de sangre", en cambio, prescinde del detalle, apuesta a presentar hechos desnudos, de manera sucinta y directa. Incluso la retórica inflamada que caracteriza otras zonas de la literatura de Rivera Indarte y que le valió el mote de autor desmesurado deja paso a una modalidad de enunciación despojada, reiterativa, que redunda en fórmulas prefijadas:

Arriaga (teniente coronel D. Fermín), cordobés; degollado por orden de Rozas el 28 de enero de 1829.

Arriagas (los hermanos); son degollados en las calles con otros muchos, del 15 al 30 de septiembre de 1840.

\footnotetext{
${ }^{11}$ Si bien se cita la primera ocasión en que el término aparece en el texto de Echeverría, chusma es un apelativo que los personajes que se mueven por el matadero reciben en nueve ocasiones.
} 
Arraigada (D. Pedro), cordobés, fusilado el 14 de abril de 1842 por orden de Rozas en el cuartel del Retiro.

Arrandeaga (D. Ignacio), vizcaíno; fusilado en el pueblo de Areco el 26 de septiembre de 1840. (Rivera Indarte “Tablas” 282-283)

Las estrategias que Rivera Indarte prioriza (el tono predominantemente neutro, la exposición sumaria de hechos sin marcas fuertes de subjetividad, la apelación a la fecha, a la estadística, a la cita de otras voces que testimonien los horrores vistos o padecidos) diferencian a "Tablas de sangre" de, por ejemplo, el resto de Rosas y sus opositores: el texto no explica, no opina, no argumenta, sino que se autodefine como la exposición rigurosa de una verdad empírica y absoluta, y no construida y parcial. La austeridad en los modos de enunciación quiere ser confundida con objetividad en la perspectiva de su autor; la violencia de los crímenes denunciados se destaca en la simpleza de una prosa desnuda que los reúne y exhibe sin ornamentar o amortiguar su crueldad.

Esa austeridad retórica constituye un elemento crucial en la representación de la violencia que "Tablas de sangre" propone. Por una vez, Rivera Indarte prescinde de la altisonancia y la grandilocuencia del discurso en su pretensión de minar, desde las letras, el poder de Rosas, para apostar por otro método: el de la acumulación precipitada. Si la amplitud del período que quiere abordar ya anticipa que el material reunido en "Tablas de sangre" será vasto, la rigidez en la enunciación y la estricta organización alfabética propiciarán un efecto acumulativo en la lectura misma, haciendo que se deslice sin contratiempos y que, en su avance apresurado, sume defunciones y atrocidades de una en una o de cientos en cientos. En ese cruce, en esa tensión entre la mesura de los modos de expresión y la desmesura cuantitativa de los crímenes superpuestos, se encuentra no sólo el principio constructivo de "Tablas de sangre", sino también la matriz de su estrategia propagandística, cuya principal orientación consiste en recrudecer la imagen de la violencia rosista, acumular y magnificar sus crímenes, sumergir al lector en una 
CATEDRAL TOMADA: Revista de crítica literaria latinoamericana / Journal of Latin American Literary Criticism Escritos sobre la violencia en la literatura argentina: “El matadero", de Esteban Echeverría y "Tablas de sangre”, de José Rivera Indarte

vertiginosa sucesión de aberraciones denunciadas con crudeza, simpleza y brevedad.

Pero ese efecto acumulativo se redobla, todavía, en otros dos rasgos que el texto recibe de su particular modo de organización. Al priorizar la distribución de las denuncias en entradas ordenadas alfabéticamente, "Tablas de sangre" desarticula la cronología de los hechos y complejiza su incrustación en una linealidad histórica de causas y efectos. De este modo, se encadenan series de entradas que provocan avances y retrocesos en el tiempo o que, en otros casos, siquiera resultan datadas:

Jaramillo, vecino de Mendoza: es asesinado en dicha ciudad el 19 de setiembre de 1829. V. Aldao. [...]

Jourdan, vasco francés; es asesinado con dos más de su nación el 4 de febrero de 1841.

Juárez (Solano); uno de los individuos que fusiló Rozas con los Reinafés después de dos años de una horrible prisión, por cómplices en el asesinato del general Quiroga, en que Rozas fue juez y ejecutor.

Junio de 1831. El tirano Rozas se aboca las causas criminales pendientes ante los jueces de Buenos Aires y hace fusilar en San José de Flores a 11 individuos. (296)

Los hechos denunciados, entonces, pasan a superponerse en una suerte de tiempo sin tiempo: el tiempo sin medida de la infamia rosista. La ausencia de una narración que enlace los episodios conectados por la causalidad y las referencias nulas a toda circunstancia que, sin justificar, pudiera contextualizarlos en un clima generalizado de agitación y violencia, potencian la pátina de sadismo irrefrenable que se atribuye a todos los actos y decisiones del tirano y sus seguidores.

Por otra parte, gracias a un criterio lábil en su elección, las entradas de “Tablas de sangre” no sólo nombrarán víctimas, sino también victimarios, lugares, meses del año, entre otras referencias todavía más asistemáticas. Más que por 
simplemente engrosar la cantidad de entradas, ese rasgo redobla el carácter acumulativo del texto porque habilita la repetición. El mismo episodio se reitera y distribuye, de este modo, en entradas diferentes que lo aluden de manera distinta, propiciando un efecto multiplicador. El asesinato de Quiroga, por caso, se refiere, además de en la entrada ya citada sobre Solano Juárez, en la que lleva su nombre, en la destinada a Barranca Yaco y en la que se dedica a su secretario, Santos Ortiz. Quiroga y sus acompañantes van en coche "al muere" más de una vez a lo largo de "Tablas de sangre".

Así, buena parte del potencial propagandístico y faccioso de "Tablas de sangre" se tensa sobre un encadenamiento de paradojas. En una primera instancia, las modalidades de enunciación rígidas, estructuradas, ordenadas, a través de las cuales se denuncian los crímenes del régimen de Rosas contribuyen, en su mesura expresiva, a incrementar la desmesura cuantitativa de las denuncias efectuadas, a remarcar lo que la violencia del rosismo tiene de inconmensurable. No obstante, cuando "Tablas de sangre" ya hace prever que el daño que Rosas hace al país resulta incalculable en el más estricto sentido de la palabra, Rivera Indarte introduce una nueva torsión bajo la forma de un prolijo y prolijamente falaz balance que pone cifras definitivas al texto y a los actos bárbaros que denuncia: "4 ENVENENADOS, 3.765 DEGOLLADOS, 1393 FUSILADOS, 722 ASESINADOS, 14920 MUERTOS EN ACCIONES DE ARMAS" (317). ${ }^{12}$

De este modo, "Tablas de sangre" combina dos estrategias de denuncia opuestas y complementarias: primero, la vertiginosa e inconmensurable acumulación de crímenes; después, la precisión de la estadística y el cálculo, que clarifica en números lo que el texto hace proliferar hasta la disipación.

\footnotetext{
${ }^{12}$ Aun sin la necesidad de contrastar los hechos y los números que "Tablas de sangre" denuncia, su balance final admitiría cuestionamientos. Por ejemplo, las cifras de muertes por el rosismo que Rivera Indarte ofrece considera a los propios soldados de Rosas muertos en combate como víctimas de la tiranía.
} 
CATEDRAL TOMADA: Revista de crítica literaria latinoamericana / Journal of Latin American Literary Criticism Escritos sobre la violencia en la literatura argentina: "El matadero", de Esteban Echeverría y "Tablas de sangre”, de José Rivera Indarte

\section{"El matadero": palabra ficticia y lectura a destiempo}

Echeverría juega la eficacia estética, política y testimonial de su texto a la capacidad representativa de una escena de violencia. Un personaje de ficción, arquetípico e idealizado, es puesto a merced de la barbarie, en un escenario que persigue, a la vez, derivaciones alegóricas y verosimilitud pseudo testimonial. Esa particular disonancia estética entre un contexto que, con sus sucesos, sus actores y su lenguaje, mereció el mote de realista, y un personaje que - también en este sentido- demuestra estar fuera de lugar cuando irrumpe en él, impregna de cierta duplicidad la apuesta política de Echeverría en su conjunto. Por un lado, la amenaza y el vejamen que el unitario padece en su cuerpo debe poder ser leído como episodio, ficticio pero factible, dentro un destino individual y, a la vez, como exemplum del destino idéntico que podría caberle a cualquier opositor al régimen. Por otro lado, el matadero y todo lo que encierra deben poder interpretarse como un escenario específico donde la barbarie se regodea, pero también como punto de condensación representativo del clima de época, en general; o, en palabras del propio Echeverría, como "foco de la federación” (Echeverría "El matadero" 120).

¿Y en qué se funda, a la vez, la barbarie específica del espacio del matadero y su representatividad respecto del contexto histórico contra el que Echeverría escribe? Desde luego, en la deshumanización del enemigo político, la animalización del unitario, la extinción del límite que une y separa vida y muerte del humano y del animal.

En el momento en que la figura del unitario se adentra en el territorio enemigo y, consecuentemente, el texto comienza a preparar su clímax narrativo, la chusma federal del matadero, dispar y caótica durante la mayor parte del cuento, se aglutina visiblemente detrás del liderazgo de Matasiete y da inicio a su reclamo de sangre, violencia e infamia. Basta que un carnicero anuncie "[a]llí viene un unitario" (114) para que la vocinglería general se detenga: "toda aquella chusma se detuvo como herida de una impresión súbita" (114). De inmediato, la irrupción de ese agente externo pone en marcha los mecanismos de reconocimiento que la 
chusma federal tiene asimilados: si la patilla en forma de $\mathrm{U}$ y la ausencia de divisa y luto lo revelan como unitario, su condición de unitario lo transforma en "perro" (115). El unitario es, en este sentido, y lejos de la figura aristotélica, un animal político: su adscripción al partido opositor legitima el revocamiento de su estatuto humano. De ahí en más, la jerga pecuaria que Echeverría atribuye a esa voz colectiva de la chusma resulta tan justificada como los vejámenes que le tocará sufrir al joven: "tusarlo", "sobarlo", domarlo, degollarlo "como al toro" (115-116) son para él, un perro unitario, destinos posibles.

La última de las comparaciones con que el unitario resulta animalizado refuerza una serie de transparentes simetrías entre el destino de los dos términos que la componen y entre las escenas que cada uno protagoniza: toro y unitario, en roles casi intercambiables, Matasiete siempre como el primus inter pares de la chusma bárbara, el resto de sus integrantes en el rol de exaltados "espectadores" (114) clamando por sangre. En efecto, la escena del toro anticipa y prepara la captura y tortura del unitario en más de un sentido: revela el goce y divertimento que provoca la ejecución de un ser vivo en el bárbaro federal, ofrece un primer episodio para narrar el aglutinamiento de la chusma ante la deseada ocasión de contemplar un acto de violencia y hace relucir el liderazgo de Matasiete. No resulta ocioso, por eso mismo, que, como señala Martín Kohan (2006), no sólo el unitario sea comparado con el toro, sino que al toro, además, se lo caracterice como “emperrado y arisco como un unitario" (Echeverría "El matadero" 111). Bajo el régimen de Rosas, un enemigo político y un animal encarnan vidas intercambiables, indistintas.

$\mathrm{Si}$ "Tablas de sangre" mantiene, en alguna medida, un diálogo sordo con "El matadero" es, justamente, por redundar en ejemplos que denuncian esa conversión de los enemigos políticos en vidas desprotegidas, animalizadas. La gama de vejámenes expuestos por Rivera Indarte es, incluso, más diversa y abundante y no se detiene siquiera cuando la vida del sometido se extingue. Mientras que la muerte del unitario es el fin de su tormento y el quiebre que dispersa a la chusma federal, "Tablas de sangre" ofrece una versión diferente de lo que ocurre luego de 
transgredido ese límite final. El cadáver del enemigo constituye, de hecho, el punto máximo de asimilación con el animal: puede ser desmembrado, desollado, convertido en objeto o atesorado como trofeo:

el coronel don Manuel Rico [...] fue muerto a bayonetazos [...] a su cadáver, después de castrarlo y de cortarle una oreja, le quitaron la piel de los dos costillares para hacer maneas. (Rivera Indarte "Tablas" 282)

Borda (el Coronel D. Facundo); es fusilado en Monte Grande (Tucumán), después de prisionero por Oribe, quien le hace cortar las orejas al cadáver y se las remite a la hija de Rozas. (285)

Violentar el cuerpo sin vida se recubre de una carga simbólica dirigida hacia terceros: si el sujeto deshumanizado recibe una muerte animal y sus restos, restos animales, no son más que carne sobre la que se puede disponer sin reparos, exhibirlos en el espacio público implica utilizarlos como mecanismo de amedrentamiento y amenaza. Así, por ejemplo, se denuncia que el cadáver de Marco Avellaneda fue mutilado luego de su ejecución: "le abrieron el pecho, lo castraron y las partes pudendas con la grasa la colgaron de un árbol y la cabeza la clavaron en un palo en medio de la plaza de Tucumán” (288).

Esa modalidad de la violencia, entre física y simbólica, que alardea de la desarticulación de la forma humana, de la destrucción de un cuerpo, se completa con otra que, una vez más, remite a "El matadero". Se trata de la espectacularización del acto bárbaro, la transformación de la violencia, la muerte, el cadáver, en objeto de admiración, celebración o divertimento: "Cuando habían degollado 10 o 20, disparaban un cohete volador, señal á la policía para que mandase carros que llevasen al cementerio a los cadáveres, tras de ellos iban los asesinos tocando una música de farsa y gritando ¿quién compra duraznos?” (276).

Así, en "El matadero" y "Tablas de sangre", como en buena parte de los textos contemporáneos escritos contra el régimen de Rosas, conviven las violencias 
de la política sobre los cuerpos, su transformación en espectáculo y divertimento, la sobreabundancia de sangre y abyección y, como presupuesto legitimador de todo lo demás, la denegación del estatuto de humano para ciertas vidas que, entregadas al arbitrio del poder soberano, se tornarán prescindibles y sacrificables como las de un animal. Esa misma serie de rasgos será retomada y resignificada por otros textos de la literatura argentina que harán eje, una vez más, en la articulación entre cuerpo, política y violencia. Sin embargo, para la inventiva ficcional como para el análisis de la crítica que perfila tradiciones y traza genealogías, "El matadero" no sólo será, en este punto, referencia principal, sino también excluyente.

La comparación con "Tablas de sangre", no obstante, pone de manifiesto que los fundamentos de esa centralidad no se juegan precisamente en la crudeza, intensidad o diversidad de los hechos de violencia que se retratan. Porque, en todo caso, el texto de Rivera Indarte alude a la puesta en acto de una serie de atrocidades que "El matadero" enuncia, insinúa o preludia, pero finalmente no narra. En sentido estricto, de hecho, sugerir que el unitario resulta ejecutado por la chusma federal implica consentir que la lectura se impregne de la perspectiva sesgada del narrador: el personaje es sometido, vejado, atado y, en el instante previo de la tortura, empujado al límite de su tolerancia, pero no es asesinado por sus captores. Deba o no atribuirse al pudor echeverriano que su particular muerte lo salve de la violación, el joven unitario revienta en sangre antes de que el relato permita catalogar de cierta o falsa la confesión del Juez: "queríamos únicamente divertirnos con él" (Echeverría "El matadero" 119). De cualquier modo, tanto en este episodio como en la decapitación del niño, que ocurre al escaparse el toro, únicas dos instancias del cuento en que la escena se tiñe de sangre humana, el cuchillo degollador del bárbaro federal no interviene en ningún sentido. En cambio, es la analogía entre la sangre animal y la sangre humana la que convoca al relato esa violencia límite. Porque si a los perros unitarios corresponde la muerte animal a través del degüello, el único en morir como perro, es decir, en recibir la muerte unitaria, es un animal: el toro, arisco y emperrado como unitario. Esa torsión de analogías consigue reforzar la simetría entre el tratamiento que el rosismo prodiga a animales y 
hombres, aun cuando, a costa de la pérdida de eficacia y dramatismo en el final, el relato prescinda de la ejecución del unitario. A último momento, Echeverría rescata a su personaje idealizado de la muerte animal para destinarlo a otra, más noble y más inverosímil.

En el texto de Rivera Indarte, desde el título hasta la última de sus entradas, la sangre aludida será siempre sangre humana vertida por el poder soberano de Rosas. Por eso, la barbarie del rosismo recrudece cuando "Tablas de sangre" acusa a los mazorqueros de "lamer el cuchillo ensangrentado" (Rivera Indarte "Tablas" 280) con que acaban de degollar a una de sus víctimas, o cuando refiere una escena en la que Manuela Rosas toca con indiferencia las manos ensangrentadas de un asesino al compartir el mate: su regodeo o su indiferencia ante el contacto con la sangre humana quiere desnudar el goce que se oculta detrás de la motivación política en los actos de violencia. En "Tablas de sangre”, Rosas y sus partidarios no son únicamente bárbaros en el ejercicio de un poder desmesurado: son también monstruos por acción o por omisión, por extasiarse o por quedar imperturbable cuando los toca la sangre ajena.

Entonces, si no en la violencia intrínseca de los actos narrados y las escenas descriptas, ¿dónde condensa "El matadero" su significación para toda una tradición de lecturas críticas y reescrituras ficcionales? ¿Por qué devino en texto representativo y modélico de un modo de escribir la violencia política, en tiempos de Rosas y después? ¿Debe atribuirse su centralidad en este terreno a un contagio propiciado por los rasgos que lo convierten en un texto excepcional en muchos otros, en uno de los pilares del canon literario nacional?

Responder afirmativamente a este último interrogante sería, probablemente, enunciar una verdad a medidas. No parece tratarse únicamente de que su lugar en el canon y la historia de las letras argentinas le done también preeminencia como texto clásico sobre la violencia, sino, sobre todo, de que los mismos rasgos que lo posicionan en el canon y la historia de las letras argentinas son los que, además, propician su centralidad en este último sentido. 
En su ensayo sobre "El matadero", Kohan señala las sucesivas capas de mediación que lo envuelven y que atenúan en él "la eficacia política de la palabra inmediata" (Kohan 173). Partiendo del presupuesto de que "toda palabra literaria es difusa" (172), Kohan remarca otras dos mediaciones, de orden temporal: la primera, una suerte de invención de distancia histórica desde la misma frase que inaugura el texto ("A pesar de que la mía es historia"); la segunda, la distancia efectiva impuesta por su publicación a destiempo. ${ }^{13}$ Ambas, en última instancia, terminarían por confluir: el carácter de inédito que mantuvo por casi tres décadas y que lo sustrajo del contexto histórico sobre el cual y contra el cual fue escrito haría que, al momento de su publicación, “"los años de Cristo de 183...” ya [resultaran] efectivamente un 'aquel tiempo' (173).

Quizá deba buscarse en esa superposición de mediaciones una de las razones principales que hacen de "El matadero" objeto de estudio sostenido para análisis críticos y modelo o punto de partida recurrente para reescrituras ficcionales en torno a la violencia política. Que las lecturas críticas, inestabilidades de estatuto textual al margen, hayan categorizado su ejercicio de la palabra literaria como principalmente ficcional, y que su trayectoria le haya concedido durante décadas el tan referido carácter de inédito no sólo son mediaciones que, de manera más o menos concluyente, amortiguan su pretensión de intervenir sobre la coyuntura a la que alude: también parecen haberlo despojado de delimitaciones históricas fuertes y facilitado la perpetua actualización que lo sitúa en el centro de un canon hipotético sobre las inflexiones de la violencia en la literatura argentina. Su capacidad de significar y resignificarse aun por fuera de los hechos, episodios, personajes y climas cultural e histórico que configuran su horizonte de escritura se encuentra, en definitiva, probada en primera instancia. Porque, como habría de ocurrir en numerosas ocasiones desde 1871 a la fecha, "El matadero" emerge del archivo para entrar en una, a la vez, tácita y nítida puesta en relación con un contexto que no es

\footnotetext{
${ }^{13}$ En parte, una lectura tal se alinea con la de Carilla, quien sostiene que, "si admitimos los dos planos esenciales que se destacan en la obra — como denuncia política y como producto artísticoel primer plano, como es obvio, no tuvo ninguna repercusión" (125).
} 
en absoluto el de su escritura efectiva, pero con el que, sin embargo, habilita un diálogo franco. Ya lo señaló Jorge Salessi: su publicación en la Revista del Río de la Plata "se ilumina leída en el contexto cultural fuertemente marcado por la epidemia de fiebre amarilla" (Salessi 57) que asolaba Buenos Aires por aquel entonces. Con la mira de la prensa porteña, atravesada por un discurso médicohigienista de creciente legitimidad, apuntando hacia mataderos y saladeros cercanos al Riachuelo como agentes contaminantes de alta responsabilidad en la catástrofe sanitaria que afronta la ciudad, el texto de Echeverría habría funcionado como punto de articulación para “dos grandes paradigmas de análisis de la cultura argentina de la segunda mitad del siglo diecinueve: civilización/barbarie y salubre/insalubre" (56). La indistinción entre vidas y muertes humanas y animales propiciada por un régimen bárbaro que pervierte los límites se homologa, así, a la mezcla nociva que dispara la alarma de los higienistas porteños.

$\mathrm{Al}$ contrario de lo que ocurre con la escritura de Rivera Indarte, procesada al ritmo de la prensa, a caballo de los últimos acontecimientos, inmiscuida en desmentidas, debates y acusaciones cruzadas, "El matadero" se deja leer, desde un primer momento, por fuera de los avatares de la estricta contingencia, pero, a la vez, en vinculación, desviada y eficaz, con su contexto de publicación diferida. Por una parte, no fue leído en su tiempo, no resultó atrapado por el enmarañado tejido de difamaciones y polémicas que fabricaron los letrados de ambos bandos. Por otra parte, el episodio que narra y el escenario que describe cristalizan un conflicto vívido y actualizable, ordenando y combinando tópicos de fuerte densidad simbólica: el regodeo y la espectacularización de la tortura, el vejamen y la violación, la animalización del enemigo político, la insalubre indistinción entre la vida y la muerte de humanos y animales, todos ellos retomados, actualizados, trastocados, en ficciones futuras que los eximen de cualquier circunscripción a una época o facción. El cuerpo capturado por los engranajes de una maquinaria de violencia que se orquesta desde un centro de poder, el sujeto despojado de su humanidad, reducido a cuerpo, a carne, empujado hacia la zona liminar donde se pliegan la vida y la muerte, lo humano y lo animal, "El matadero" ficcionaliza esa 
escena, por primera vez para la literatura argentina, y corrobora una doble potencia y eficacia: la potencia y eficacia de la escena en sí misma y la potencia y eficacia de su versión ficcional, cuya intrínseca mediación, que afloja las ataduras de la referencia histórica, se redobla aún más por el particular destino que correría el texto.

En este sentido, "Tablas de sangre", como el resto de la literatura de Rivera Indarte y, podría afirmarse, como todas las versiones extremas de la literatura y la prensa antirrosista, representa el reverso exacto de "El matadero". Los actos de violencia a los que hace referencia, si bien desnudan, por acumulación, una lógica y una sistematicidad que los hilvana, aluden a episodios concretos: se los data, se los sitúa geográficamente, se enuncian nombres propios de víctimas y victimarios. $\mathrm{Al}$ pretender denunciar cada una de las atrocidades cometidas por el régimen de Rosas, desde grandes matanzas hasta infamias hipotéticas de la vida privada (el hecho de hacer de Manuelita, su manceba, por ejemplo), "Tablas de sangre” juega su eficacia política y propagandística a ese vínculo estrecho con su referente histórico, casi clausurando toda lectura que lo exceda o lo relativice.

Como si intuyera que la capacidad de significación política de la ficción responde a un régimen distinto, el texto de Echeverría elude la exhaustividad de muestrario absoluto para apostar por la configuración de una escena que se quiere, a la vez, simbólica y posible, particular y arquetípica. Así, no sobrecarga su versión del rosismo a través de la sumatoria de crímenes atroces y presuntamente verídicos. Aunque virulento en sí mismo, si el relato de los vejámenes padecidos por el joven unitario recrudece hasta sugerir más de lo que en efecto enuncia, es porque lo envuelve una atmósfera tan violenta como el episodio que marca su clímax, porque lo antecede la mirada de un narrador que, irónico o sentencioso pero siempre despreciativo, exhibe sin contemplaciones la perfidia y vulgaridad de la chusma federal; porque la tortura y humillación se cometen y celebran en una fiesta monstruosa, una primera fiesta del monstruo; porque las anticipa y acompaña un rosario de amenazas que se concreta parcialmente pero que se impregna en la 
CATEDRAL TOMADA: Revista de crítica literaria latinoamericana / Journal of Latin American Literary Criticism Escritos sobre la violencia en la literatura argentina: "El matadero", de Esteban Echeverría y "Tablas de sangre”, de José Rivera Indarte

lectura con la fuerza de lo sucedido. ${ }^{14} \mathrm{Y}$, también porque, a la par de las manos que capturan, someten, atan, desnudan, se va escuchando la voz del bárbaro, con su jerga y su entonación, prometiendo que lo peor para el joven unitario está por venir.

\section{Bibliografía}

Area, Leila. "Proferir lo inaudito: “Tablas de sangre”, de José Rivera Indarte”. The Colorado Review of Hispanic Studies, vol. 4. (2006): 189-204.

Carilla, Emilio. "Juan María Gutiérrez y El Matadero". Anuario de Letras, vol. XXXII. (1994): 100-144.

Cragnolini, Monica. Extraños animales. Filosofía y animalidad en el pensar contemporáneo. Buenos Aires: Prometeo, 2016.

Derrida, Jacques. El animal que luego estoy si(gui)endo. Madrid: Trotta, 2008.

Echeverría, Esteban. “Tercera carta de Echeverría a Rivera Indarte”. Alberto Palcos. Echeverría y la democracia argentina. Buenos Aires: El Ateneo, 1941.

. "Segunda carta de Echeverría a Rivera Indarte". En: Alberto Palcos, Echeverría y la democracia argentina. Buenos Aires: El Ateneo, 1941. . "El matadero". La cautiva / El matadero. Buenos Aires: Colihue, 2006.

Giorgi, Gabriel. Formas comunes. Animalidad, cultura, biopolítica. Buenos

Aires: Eterna Cadencia, 2014.

Gutiérrez, Juan María. “Advertencia”. Esteban Echeverría. La cautiva / El matadero. Buenos Aires: Colihue, 2006.

${ }^{14}$ Quizá nada evidencie mejor la potencia del clima violento generado hacia el final de "El matadero", incluso por sobre la violencia en sí de los actos narrados, que el hecho de que Noé Jitrik, precisamente en un análisis textual riguroso y lúcido, sostenga que el joven unitario "es asesinado" (Jitrik 84). 
Iglesia, Cristina. "Mártires o libres: un dilema estético. Las víctimas de la cultura en 'El matadero' de Echeverría y en sus reescrituras”. Letras y divisas. Ensayos sobre literatura y rosismo. Buenos Aires: Santiago Arcos, 2004.

Jitrik, Noé. "Forma y significación en El matadero de Esteban Echeverría". El fuego de la especie. Buenos Aires: Siglo XXI, 1971.

Kohan, Martín. "Las fronteras de la muerte". Alejandra Laera y Martín Kohan (comps.). Las brújulas del extraviado. Para una lectura integral de Esteban Echeverría. Rosario: Beatriz Viterbo, 2006.

Lojo, María Rosa. "Facundo: la barbarie como poesía de lo original/originario". Letras, n²3-24, (Buenos Aires, 1990-1991): 59-84.

Lynch, John. Juan Manuel de Rosas: 1829-1852. Buenos Aires: Emecé, 1997.

Mitre, Bartolomé. "Biografía de José Rivera Indarte”. Poesías de José Rivera Indarte. con una biografía del autor, escrita por el coronel de artillería D. Bartolomé Mitre. Buenos Aires: Imprenta de Mayo, 1853.

Piglia, Ricardo. "Echverría y el lugar de la ficción". La Argentina en pedazos. Buenos Aires: Ediciones de la Urraca, 1993.

Rojas, Ricardo. Historia de la literatura argentina. Vol. II. Buenos Aires: Losada, 1948.

Rivera Indarte, José. Rosas y sus opositores. Buenos Aires: Imprenta de Mayo, 1853.

. "Respuesta de Rivera Indarta a 'Un Oriental”". En: Alberto Palcos Echeverría y la democracia argentina. Buenos Aires: El Ateneo, 1941a. . "Tercera carta de Rivera Indarte a Echeverría". En: Alberto Palcos Echeverría y la democracia argentina. Buenos Aires: El Ateneo, $1941 \mathrm{~b}$.

Rosas, Juan Manuel de. Instrucciones a los mayordomos de estancias. Buenos Aires: Claridad, 2010.

Saldías, Adolfo. Historia de la Confederación Argentina. Tomo II. Buenos Aires: Eudeba, 1978.

Salessi, Jorge. Médicos, maleantes y maricas. Rosario: Beatriz Viterbo, 1995.

Sarmiento, Domingo. Facundo. Buenos Aires: Colihue, 2006. 
CATEDRAL TomAdA: Revista de crítica literaria latinoamericana / Journal of Latin American Literary Criticism Escritos sobre la violencia en la literatura argentina: "El matadero", de Esteban Echeverría y "Tablas de sangre”, de José Rivera Indarte

Viñas, David. Literatura argentina y realidad política. De Sarmiento a Cortázar.

Buenos Aires: Ediciones Siglo Veinte, 1971.

\section{Publicaciones periódicas consultadas:}

El Grito Arjentino, n²8. Montevideo, 6 junio, 1839.

Muera Rosas!, n ${ }^{\circ}$, Montevideo, 23 diciembre 1841.

Zurian de la Fuente, Carla Isadora y Claudio Palomares Salas. "El Café de Nadie: aproximaciones al mito." Letras hispanas (2015): 19-29. 